\title{
A multicenter cross-sectional study on the prevalence of overactive bladder and its impacts on the quality of life in gynecologic outpatients
}

Do Young Kim, MD¹, Da Hae Jang, MD¹, Hyun Jin Kim, MD¹, Sa Ra Lee, MD¹, Myung Jae Jeon, MD², Jung-Ho Shin, $\mathrm{MD}^{3}$, Hee Dong Chae, MD'

Department of Obstetrics and Gynecology, ${ }^{1}$ Asan Medical Center, University of Ulsan College of Medicine, ${ }^{2}$ Seoul National University Hospital, Seoul National University College of Medicine, ${ }^{3}$ Korea University Guro Hospital, Korea University College of Medicine, Seoul, Korea

\section{Objective}

The present study assessed the prevalence of overactive bladder (OAB) symptoms in gynecologic outpatients and the effects of $O A B$ on a patient's quality of life.

\section{Methods}

The survey was completed by adult female patients who visited the gynecology clinic for examination or treatment of gynecologic conditions. The subjects who met the exclusion criteria were excluded. The survey included a questionnaire assessing general characteristics, the purpose of the visit, diagnosis, and the presence or absence of $O A B$. The subjects were asked whether they were under medical treatment for OAB symptoms, and the degree of discomfort in daily activities was evaluated.

Results

In total, 1,990 female subjects visiting the gynecology clinics of 4 different institutions were recruited. On $O A B$ Symptom Score, 188 subjects responded with scores of $\geq 2$ for question \#3 ( $\geq 1$ time(s) weekly). The severity of $O A B$ symptoms was as follows: 345 subjects had mild $O A B, 127$ subjects had moderate $O A B$, and 12 subjects had severe OAB. The prevalence of OAB symptoms was $10.30 \%$.

\section{Conclusion}

The present study confirmed that $O A B$ symptoms are common, with a prevalence of $10.30 \%$. Patients with $O A B$ symptoms frequently neglect to seek medical intervention. Our findings will help inform patients to recognize their condition and seek medical assistance, especially in gynecologic outpatient clinics.

Keywords: Overactive bladder; Prevalence; Quality of life

\section{Introduction}

Overactive bladder $(O A B)$ is a syndrome characterized by urinary urgency, frequency, and nocturia. OAB may or may not be accompanied by urgent urinary incontinence in the absence of urinary infections or other causative diseases [1,2]. The European Prospective Investigation into Cancer and Nutrition (EPIC) Study, conducted in Canada, Germany, the United Kingdom, Italy, and Sweden, reported that OAB prevalence was $10.8 \%$ and $12.8 \%$ for men and women aged $\geq 18$ years, respectively, with an overall prevalence of $11.8 \%$ [3]. In the United States, the reported prevalence of $O A B$
Received: 2019.06.17. Revised: 2019.10.15. Accepted: 2019.10.29. Corresponding author: Hee Dong Chae, MD

Department of Obstetrics and Gynecology, Asan Medical Center, University of Ulsan College of Medicine, 88 Olympic-ro 43-gil,

Songpa-gu, Seoul 05505, Korea

E-mail: hdchae@amc.seoul.kr

https://orcid.org/0000-0003-0129-9422

Articles published in Obstet Gynecol Sci are open-access, distributed under the terms of the Creative Commons Attribution Non-Commercial License (http://creativecommons. org/licenses/by-nc/3.0/) which permits unrestricted non-commercial use, distribution, and reproduction in any medium, provided the original work is properly cited.

Copyright $\odot 2020$ Korean Society of Obstetrics and Gynecology 


\title{
Obstetrics \& Gynecology Science
}

\author{
Vol. 63, No. 2, 2020
}

was $16.0 \%$ and $16.9 \%$ for men and women, respectively, and $16.5 \%$ overall [4]. In Korea, a study with a similar design using a phone call questionnaire survey of 2,000 Koreans reported a high prevalence at $11.2 \%$ and $18.4 \%$ in men and women aged $\geq 40$ years, respectively [5].

Patients who experience $O A B$ symptoms are prone to isolation from social activities and interpersonal relationships, and the actual effect of $O A B$ on the quality of life is more detrimental than the effects of diabetes [6]. Although OAB has a significant impact on the quality of life in adult populations [7], most patients do not receive professional treatment, and they bear the discomfort associated with their condition because they feel ashamed and are not aware that their condition can be treated or that they can accept the disease as part of daily life. Although OAB is reportedly more prevalent among women than men in Korea, the prevalence of $O A B$ and the impact of $O A B$ on the quality of life in women admitted to the department of obstetrics and gynecology for an examination or for an obstetric-gynecologic disease has not been evaluated. Thus, this study was conducted to investigate the prevalence of $O A B$ and the impact of $O A B$ on occupational activities, mental health, and daily life among female patients admitted to the department of obstetrics and gynecology.

\section{Materials and methods}

A census survey was conducted among female patients aged $\geq 18$ years who were examined at the department of obstetrics and gynecology or admitted to the same department for an obstetric-gynecologic disease at Asan Medical Center, Ewha University Mokdong Hospital, Korea University Guro Hospital, or Seoul National University Hospital. The census survey was conducted using the Overactive Bladder Symptom Score (OABSS) Questionnaire to investigate the age, weight, height, history of medical disease and surgery, reason for visiting the department of obstetrics and gynecology, obstetricgynecologic diagnosis, and the presence or absence of $O A B$ syndrome (Appendix 1). Additionally, patients were asked if $O A B$ caused any discomfort in daily life. Nine items from the Korean version of the King's Health Questionnaire (1998, Version 8) were used to investigate the effects of $O A B$ on occupational activities, mental health, and sex life. Patients who did not understand the questionnaire, pregnant women or women who had given birth in the last 6 months, patients who currently had a urinary tract infection or were taking medications that could affect bladder function, and patients receiving treatment for $O A B$ symptoms were excluded.

Total OABSS scores of $3-5,6-11$, and $\geq 12$ points suggested mild, moderate, and severe $O A B$, respectively. The OABSS scores for each item and the total scores between the patients with and without $O A B$ symptoms were compared using the mean and standard deviation values. The severity of each symptom, based on the sum of the total OABSS scores of the patients with $O A B$ syndrome, was compared to the severity levels on the quality of life survey. SPSS version 13.0 Statistics Package (SPSS, Inc., Chicago, IL, USA) was used to perform the Student's t-test, analysis of variance, and Spearman rank correlation test with a level of statistical significance set at $P \leq 0.05$.

\section{Results}

A total of 1,490 patients were recruited from the 4 hospitals. The patients had a mean age of $48.1 \pm 12.9$ years, a mean height of $158.0 \pm 6.0 \mathrm{~cm}$ and a mean weight of $56.7 \pm 8.0 \mathrm{~kg}$. The mean number of past births was $1.8 \pm 1.2$ per woman, and vaginal delivery accounted for $78.2 \%$ of the births. Additionally, 189 women (9.50\%) had previously undergone pelvic surgery and 970 women (49.9\%) were menopausal (Table 1).

Table 1. Patient characteristics

\begin{tabular}{lc}
\hline Characteristics & Value \\
\hline Age (years) & $48.06 \pm 12.85$ \\
Height $(\mathrm{cm})$ & $158.01 \pm 6.00$ \\
Weight $(\mathrm{kg})$ & $56.68 \pm 8.00$ \\
Gravida (times) & $2.96 \pm 2.09(3)$ \\
Parity (times) & $1.83 \pm 1.22(2)$ \\
Mode of delivery & \\
Vaginal delivery & $1,134(78.21)$ \\
Cesarean section & $286(19.31)$ \\
Vaginal delivery + Cesarean section & $36(2.48)$ \\
Menopause & $970(49.87)$ \\
Previous pelvic surgery & $189(12.68)$ \\
\hline
\end{tabular}

Values are presented as mean \pm standard deviation (median) or number (\%). 


\section{Obstetrics \& Gynecology Science}

Do Young Kim, et al. The prevalence of OAB in GY patients

A regular examination was the most common (27.9\%) reason for visiting the department of obstetrics and gynecology, followed by a diagnosis of tumor in the uterus or the ovaries $(23.0 \%)$, and abnormal findings suggestive of cervical cancer (8.6\%) (Table 2).

On the OABSS Questionnaire, 209 women (10.6\%) scored at least 2 points on the third question (urgency score):

Table 2. Reasons for visiting the department of obstetrics and gynecology

\begin{tabular}{lc}
\hline Reasons & Number (\%) \\
\hline Screening & $85(27.9)$ \\
Uterine mass & $50(16.4)$ \\
Adnexal mass & $20(6.57)$ \\
Abnormal cytology of uterine cervix & $26(8.55)$ \\
Others & $123(40.4)$ \\
\hline
\end{tabular}

98 women (4.96\%) scored 2 points (at least once per week), $56(2.83 \%)$ scored 3 points (once per day), 42 (2.13\%) scored 4 points (2-4 times per day) and $13(0.66 \%)$ scored 5 points ( $\geq 5$ times per day). Based on the scoring criteria, 345 patients (17.3\%) had mild OAB, 127 (6.4\%) had moderate $O A B$ and $12(0.6 \%)$ had severe $O A B$. The prevalence of OAB symptoms was $10.30 \%(n=205)$ (Table 3 ).

Significant differences in the severity of OABSS were observed based on whether the patient was menopausal. Menopausal women experienced more severe symptoms of OAB. The mean OABSS of menopausal/non-menopausal women was 4.30/3.41 $(P<0.05)$. However, hormone therapy in these patients did not significantly improve $O A B$ symptoms. The mean OABSS was 4.12 in patients treated with hormone therapy and 4.27 without hormone therapy $(P=0.34)$. History of pregnancy and childbirth was also significantly associated with OABSS: the severity of OABSS in-

Table 3. Results of Overactive Bladder Symptom Score

\begin{tabular}{|c|c|c|c|}
\hline Symptoms & Frequency & Score & Number (\%) \\
\hline \multirow[t]{3}{*}{ How often did you urinate from morning till bedtime? } & $\leq 7$ times & 0 & $1,372(69.2)$ \\
\hline & 8-14 times & 1 & $570(28.8)$ \\
\hline & $\geq 15$ times & 2 & $40(2.0)$ \\
\hline \multirow[t]{4}{*}{ How many times did you get up during the night to urinate? } & 0 times & 0 & $267(13.4)$ \\
\hline & 1 time & 1 & $189(9.5)$ \\
\hline & 2 times & 2 & $675(34.0)$ \\
\hline & $\geq 3$ times & $>3$ & $856(43.1)$ \\
\hline \multirow[t]{6}{*}{ How often did you feel a sudden irresistable urge to urinate? } & Never & 0 & $1,456(73.7)$ \\
\hline & Less than once per week & 1 & $311(15.7)$ \\
\hline & More than once per week & 2 & $98(5.0)$ \\
\hline & Once per day & 3 & $56(2.8)$ \\
\hline & 2-4 times per day & 4 & $42(2.1)$ \\
\hline & $\geq 5$ times per day & 5 & $13(0.1)$ \\
\hline \multirow[t]{6}{*}{ How often did you leak urine after feeling an urge to urinate? } & Never & 0 & $1,231(62.2)$ \\
\hline & Less than once per week & 1 & $155(7.8)$ \\
\hline & More than once per week & 2 & $489(24.7)$ \\
\hline & Once per day & 3 & $66(3.3)$ \\
\hline & 2-4 times per day & 4 & $29(1.5)$ \\
\hline & $\geq 5$ times per day & 5 & $9(0.5)$ \\
\hline \multirow[t]{4}{*}{ Total score } & & $0-2$ & $1,506(75.7)$ \\
\hline & & $3-5$ & $345(17.3)$ \\
\hline & & $6-11$ & $127(6.4)$ \\
\hline & & $12-15$ & $12(0.6)$ \\
\hline
\end{tabular}




\title{
Obstetrics \& Gynecology Science
}

\author{
Vol. 63, No. 2, 2020
}

creased as a woman's number of pregnancies and childbirths increased $(P<0.05)$. However, there was no change in the severity of OABSS according to the method of delivery, and natural birth and cesarean birth did not significantly affect the severity of $O A B$ symptoms. History of pelvic surgery also had no significant impact on the severity of OABSS $(P=0.42)$ (Table 4).

\section{Discussion}

This is the first study to investigate the prevalence of $O A B$ from the perspective of obstetrics and gynecology. Numerous studies have been conducted on the prevalence of $O A B$ in foreign countries. A phone call survey of 2,427 women in the United States found the prevalence of OAB symptoms to be $16.9 \%$ [4]. A study conducted in Europe and Canada of a relatively large population of 19,165 women reported the prevalence of $O A B$ to be $12.8 \%$ [3]. A higher prevalence rate of $\geq 20 \%$ was observed in a Japanese study comparing Japan to Europe and the United States $[4,8,9]$. In Korea, a

Table 4. Factors correlated with Overactive Bladder Symptom Score (OABSS)

\begin{tabular}{|c|c|c|c|c|}
\hline Factors & & Number (\%) & OABSS & $P$-value \\
\hline \multirow[t]{2}{*}{ Menopause } & Yes & $740(49.87)$ & 4.30 & $<0.05$ \\
\hline & No & 747 (50.13) & 3.41 & \\
\hline \multirow{2}{*}{$\begin{array}{r}\text { Hormone } \\
\text { therapy }\end{array}$} & Yes & $286(33.10)$ & 4.12 & NS \\
\hline & No & $578(66.90)$ & 4.27 & \\
\hline \multirow{2}{*}{$\begin{array}{l}\text { Gravida } \\
\text { number }\end{array}$} & $\leq 3$ & $728(48.85)$ & 3.26 & $<0.05$ \\
\hline & $>3$ & 762 (51.15) & 4.51 & \\
\hline \multirow{2}{*}{$\begin{array}{l}\text { Parity } \\
\text { number }\end{array}$} & $\leq 2$ & 844 (56.64) & 3.39 & $<0.05$ \\
\hline & $>2$ & $646(43.36)$ & 4.43 & \\
\hline \multirow[t]{3}{*}{$\begin{array}{l}\text { Mode of } \\
\text { delivery }\end{array}$} & $\begin{array}{l}\text { Vaginal } \\
\text { delivery }\end{array}$ & $1,134(78.21)$ & 3.28 & NS \\
\hline & $\begin{array}{c}\text { Cesarean } \\
\text { section }\end{array}$ & $286(19.31)$ & 3.10 & \\
\hline & Both & $36(2.48)$ & 3.33 & \\
\hline \multirow{2}{*}{$\begin{array}{l}\text { Surgery } \\
\text { history }\end{array}$} & Yes & $189(12.68)$ & 3.67 & NS \\
\hline & No & $1,301(87.32)$ & 3.55 & \\
\hline
\end{tabular}

NS, not significant. phone call survey of 2,000 patients in the department of urology demonstrated a prevalence rate of $14.3 \%$ [5]. However, aside from that phone call survey, no survey has been conducted among patients who have visited the hospital, and furthermore, never in the department of obstetrics and gynecology.

In this study, the prevalence of OAB symptoms was found to be $10.3 \%$, which is lower than the prevalence reported in the United States, Europe, and Canada $[4,8,10]$. This may be due to a lack of awareness of OAB as a disease or patients' cultural differences and their tendency to be embarrassed about OAB. It is estimated that the number of women who wish to be treated at a hospital may be lower than what is suggested by the prevalence rate. OAB symptoms can lower the quality of life, restrict daily activities, and lead to a loss of self-esteem more significantly than diabetes and other chronic diseases [6]. Physicians must actively raise awareness that $O A B$ symptoms can be improved or completely cured through active treatment. This can relieve feelings of embarrassment and encourage patients to visit the hospital due to symptoms.

There are several limitations to this study. First, the patient sample in this study was not representative of the entire population of Korean women. The study group was limited to patients who visited gynecology clinics. Since the prevalence of OAB symptoms increases with age, we could investigate the differences in the prevalence of $O A B$ between different age groups in Korea. This knowledge could promote more active patient participation in medical consultations and help in the determination of treatment methods. The second limitation of this study was the presence of incomplete responses. Even though some subjects did not complete the questionnaires, their answers were included in the results. Third, the study included patients with a history of pelvic organ prolapse surgery. This may have affected the overall prevalence of $O A B$.

Further information about the prevalence of $O A B$ and the distribution of symptoms for each age group would be helpful for the treatment of patients with OAB. According to the International Urogynecological Association and the International Continence Society criteria, the possibility of urinary tract infection or other causes must be eliminated before diagnosing $O A B$. We therefore tried to exclude all patients that met these criteria [2]. However, it may be difficult to accurately diagnose $O A B$ and calculate its prevalence 


\section{Obstetrics \& Gynecology Science}

Do Young Kim, et al. The prevalence of OAB in GY patients

based only on the results of the questionnaire without any additional tests including urinalysis. Despite these limitations, this study is significant because OAB was diagnosed based on the results of a face-to-face survey and examination of the patients admitted to hospital, not based on a phone call survey. Finally, this is the first study of female patients from the viewpoint of obstetrics and gynecology in these 4 tertiary medical institutions.

In conclusion, we found that the prevalence of $O A B$ among Korean women was approximately $12.28 \%$, and $O A B$ symptoms were significantly correlated with menopause and a history of pregnancy and childbirth. Additionally, we found that a history of hormone therapy, the method of childbirth, and a history of pelvic surgery did not significantly affect $O A B$. Despite some limitations, this study demonstrates the need for an urogynecologic approach to obstetric-gynecologic patients, with an aim to increase the awareness and improve the treatment of $O A B$ in the department of obstetrics and gynecology.

\section{Conflict of interest}

No potential conflict of interest relevant to this article was reported.

\section{Ethical approval}

This study was approved by the Institutional Review Boards (IRB) of each of the 4 hospitals (Asan Medical Center, No. 2011-0211; Ewha University Mokdong Hospital; Korea University Guro Hospital; or Seoul National University Hospital).

\section{Patient consent}

Written informed consent was obtained.

\section{References}

1. Abrams P, Cardozo L, Fall M, Griffiths D, Rosier P, Ulmsten $U$, et al. The standardisation of terminology of lower urinary tract function: report from the Standardisation Sub-committee of the International Continence Society. Neurourol Urodyn 2002;21:167-78.

2. Haylen BT, de Ridder D, Freeman RM, Swift SE, Berghmans $B$, Lee J, et al. An International Urogynecological Association (IUGA)/International Continence Society (ICS) joint report on the terminology for female pelvic floor dysfunction. Neurourol Urodyn 2010;29:4-20.

3. Irwin DE, Milsom I, Hunskaar S, Reilly K, Kopp Z, Herschorn $S$, et al. Population-based survey of urinary incontinence, overactive bladder, and other lower urinary tract symptoms in five countries: results of the EPIC study. Eur Urol 2006;50:1306-14.

4. Stewart WF, Van Rooyen JB, Cundiff GW, Abrams P, Herzog AR, Corey $R$, et al. Prevalence and burden of overactive bladder in the United States. World J Urol 2003;20:327-36.

5. Lee YS, Lee KS, Jung JH, Han DH, Oh SJ, Seo JT, et al. Prevalence of overactive bladder, urinary incontinence, and lower urinary tract symptoms: results of Korean EPIC study. World J Urol 2011;29:185-90.

6. Abrams P, Kelleher CJ, Kerr LA, Rogers RG. Overactive bladder significantly affects quality of life. Am J Manag Care 2000;6:S580-90.

7. Dugan E, Cohen SJ, Robinson D, Anderson R, Preisser J, Suggs $P$, et al. The quality of life of older adults with urinary incontinence: determining generic and conditionspecific predictors. Qual Life Res 1998;7:337-44.

8. Hunskaar S, Lose G, Sykes D, Voss S. The prevalence of urinary incontinence in women in four European countries. BJU Int 2004;93:324-30.

9. Homma Y, Yamaguchi O, Hayashi K; Neurogenic Bladder Society Committee. An epidemiological survey of overactive bladder symptoms in Japan. BJU Int 2005;96:1314-8.

10. Corcos J, Schick E. Prevalence of overactive bladder and incontinence in Canada. Can J Urol 2004;11:2278-84. 


\section{Obstetrics \& Gynecology Science}

Vol. 63, No. 2, 2020

Appendix 1. Overactive Bladder Symptom Score (OABSS) Questionnaire

How often have you had the symptoms listed below? Pick one option that best represents your condition in the last one week and circle the corresponding score.

\begin{tabular}{|c|c|c|c|}
\hline Question & & Frequency & Score \\
\hline \multirow[t]{3}{*}{1} & How often did you urinate from the morning till the bedtime? & $\leq 7$ times & 0 \\
\hline & & 8-14 times & 1 \\
\hline & & $\geq 15$ times & 2 \\
\hline \multirow[t]{4}{*}{2} & How many times did you get up during the night to urinate? & 0 times & 0 \\
\hline & & 1 time & 1 \\
\hline & & 2 times & 2 \\
\hline & & $\geq 3$ times & 3 \\
\hline \multirow[t]{6}{*}{3} & How often did you feel a sudden irresistable urge to urinate? & Never & 0 \\
\hline & & Less than once per week & 1 \\
\hline & & More than once per week & 2 \\
\hline & & Once per day & 3 \\
\hline & & $2-4$ times per day & 4 \\
\hline & & $\geq 5$ times per day & 5 \\
\hline \multirow[t]{6}{*}{4} & How often did you leak urine after feeling an urge to urinate? & Never & 0 \\
\hline & & Less than once per week & 1 \\
\hline & & More than once per week & 2 \\
\hline & & Once per day & 3 \\
\hline & & 2-4 times per day & 4 \\
\hline & & $\geq 5$ times per day & 5 \\
\hline Total score: & & & points \\
\hline
\end{tabular}

Overactive bladder is diagnosed for total scores $\geq 3$ points with at least 2 points for question 3 . Overactive bladder is considered mild for total scores $\leq 5$ points, moderate for total scores of $6-11$ points, and severe for total scores $\geq 12$ points. 